\title{
INFLUENCE OF SILICA NANOPARTICLES ON THE THERMOMECHANICAL PROPERTIES OF RECYCLED POLYSTYRENE
}

\author{
A. PEREZ-GUERREROI, J. LISPERGUER ${ }^{2 *}$, F. ORELLANA ${ }^{2}$ \\ ${ }^{I}$ Centro de Investigación de Polímeros Avanzados. CIPA. Universidad del Bío-Bío, Av. Collao 1202-Concepción-Chile. \\ ${ }^{2}$ Depto. Química, Facultad de Ciencias, Universidad del Bío-Bio, Av. Collao 1202-Concepción-Chile.
}

(Received: April 6, 2011 - Accepted: August 18, 2011)

\begin{abstract}
Polystyrene from packing materials (rPS) was reinforced with 1,3 and $5 \%$ of silica prepared by the sol-gel method, through a blending process . The thermal, morphological and mechanical properties were compared with those of the virgin polystyrene (PS). The results show that the glass transition temperature (Tg), storage modulus (E') and impact strength of the pure rPS and silica-rPS composites were higher than those of virgin PS. Thermogravimetric analysis revealed that the thermal stability of virgin PS was slightly greater than that of the rPS. The addition of silica to rPS increased their thermal stability to similar values of the virgin PS.

SEM studies showed that the silica nanoparticles had an uniform size but its dispersion into the polymer matrix was not homogeneous.

These results suggest that postconsumer PS can be used to obtain composite materials with good mechanical and thermal properties.
\end{abstract}

Keywords: Polystyrene, nanocomposites, silica, thermal properties, morphology

\section{INTRODUCTION}

The use of PS has increased significantly leading to growing concern over its effects on the environment and the dwindling space in landfills.

One way to minimize this adverse amount of waste is by reusing and recycling PS products. Two problems emerge during the recycling of plastics: how to characterize postconsumer plastics and how to increase the mechanical properties of recycled polystyrene $e^{1,2,3}$.

Several methods to increase the use of rPS have been investigated. Some of this research focuses on replacing virgin PS in the manufacture of final products.

Reports have shown that the incorporation of large amounts of rPS into blends does not decrease the mechanical and rheological properties of virgin PS. ${ }^{4}$

The use of rPS in blends with other virgin thermoplastics that have a low PS content (5\%) such as polyurethane (PU), has been reported. The addition of rPS was found to change the mechanical behavior and the final morphology of the compositions ${ }^{5}$.

The mechanical properties of rPS have also been improved by addition of other thermoplastic polymers such as polypropylene $(\mathrm{PP})^{6,7}$, polymethyl methacrylate $(\mathrm{PMMA})^{8}$, polyethylene $(\mathrm{PE})^{9}$, polyamide $(\mathrm{PA})^{10}$ and lignocellulosic fillers ${ }^{11,12}$. These blends increased the impact strength of the rPS without decreasing its tensile strength too much.

Polymer nanocomposites are particulate-filled composites in which the reinforcing phase has at least one dimension in the nanometer $\left(10^{-9}\right)$ range $^{13}$.

These materials exhibit a dramatic improvement in stiffness, strength, and thermal properties compared to polymers, or conventional composite materials. The superior properties result from the fact that nanocomposites have much larger surface area per unit volume, since one of the constituents has dimensions that range between 1 and $100 \mathrm{~nm}$. Since most of chemical and physical interactions are influenced by surfaces, the properties of a nanostructured material can be substantially different from those of a conventional composite material, with the same composition.

A lot of works have been dealt with various types of nanofillers and various methods of polymer / nanocomposite technology ${ }^{14,15,16}$.

Multiple techniques can be used to analyze nanocomposites and quantify the filler dispersion and the material morphology. The interrelation between rhelogical, thermal and mechanical properties and nanocomposite morphology has been extensively studied.

Many studies regarding virgin PS- nanofiller composites have been reported. PS- organoclay nanocomposites prepared by melt intercalation show an increase of Young's modulus at different contents of organoclay when compared with the modulus of the neat resin but a linear relationship between the amount of organoclay and Young's modulus was not observed ${ }^{17}$.

Natural zeolite ${ }^{18}$, alumina ${ }^{19}$, metal oxides ${ }^{20,21}$, organophilic modified layered silicates ${ }^{22,23}$, and single and multiwall carbon nanotubes ${ }^{24,25}$, have been used for the modification of virgin PS.

There is little information on studies about recycled materials from expanded polystyrene (EPS), that is one of the most abundant postconsumer PS waste. On the other hand, findings from other articles have shown that EPS tended to have poorer material properties than raw $\mathrm{PS}^{26,27}$; this hampered the demand for the former material.

In the present study, nanocomposites based on rPS from EPS reinforced by silica nanoparticles at various weight fractions, and prepared with a conventional melt mixing procedure, were studied and compared with virgin PS.

The aim of the work was to study the effects of silica nanoparticles on the thermal and mechanical properties of EPS .

The thermal behaviour of the composites was studied by differential scanning calorimetry (DSC), dynamic mechanical analysis (DMA), thermogravimetric analysis (TGA) and melt flow indexer (MFI).

The dispersion of the nanoparticles into de polymeric matrix was studied by scanning electron microscopy (SEM).

Mechanical property as impact strength was also studied.

\section{EXPERIMENTAL}

\section{Materials}

Silica source used in this study was tetraethoxysilane (TEOS) with $98 \%$ purity supplied by MERCK.

The silica was prepared by the sol-gel method dissolving TEOS in ethanol. The solution was stirred and heated to $50^{\circ} \mathrm{C}$ until well blended. Distilled water was subsequently added to a molar ratio $\mathrm{H}_{2} \mathrm{O} / \mathrm{TEOS}$ of 20 and $\mathrm{HCl}$ was added to maintain a $\mathrm{pH}$ of $4-5$. The resulting mixture was stirred vigorously until gelation occured and then was maintained for 1 hour.Residual solvent was removed and the solid was dried at $60^{\circ} \mathrm{C}$ to constant weight for 24 hours.

EPS from packing materials from supermarkets was used in this study. The plastic waste was washing with hot water and drying to constant weight for 8 hours at $80^{\circ} \mathrm{C}$. Afterwards, EPS was pressed at $120^{\circ} \mathrm{C}$ and 4 bar of pressure to eliminate the high air content in EPS. Afterwards, the material was pre-ground in a knife mill to an average size of 1 to $2 \mathrm{~cm}$ and then oven dried at $80^{\circ} \mathrm{C}$ for 24 hours.

Virgin polystyrene (PS STYRON 678 D) with a melt flow index value of $10 \mathrm{~g} / 10 \mathrm{~min}$ and a density of $1.05 \mathrm{~g} / \mathrm{cm}^{3}$ was supplied by the Dow Chemical Co.

\section{Melt blending process}

Composites of silica nanoparticles - rPS were prepared at three content percentage of silica : 1,3 , and 5 weight $\%$.

In order to evaluate the influence of silica on the thermal and mechanical properties of the rPS, virgin and recycled PS without silica were also prepared. 
The mixes were prepared in a Thermo Haake Polydrive Rheomix 600 supplied with a roller blade mixer, set at a heating temperature of $190^{\circ} \mathrm{C}$ with a rotational speed of the mixer's rollers $60 \mathrm{rpm}$, for $15 \mathrm{~min}$.

The extrudates were then molded in a laboratory press at $190^{\circ} \mathrm{C}$ and 120 bar of pressure to produce impact bar specimens for the property evaluations of the silica-rPS composites.

\section{Thermal, morphological and mechanical analysis}

The Tg values of the virgin PS, rPS and silica-rPS from the Rheomix, were determined with a differential scanning calorimeter (DSC $822^{\mathrm{e}}$, Mettler Toledo) equipped with a thermal analysis data $\mathrm{STAR}^{\mathrm{e}}$ software system.

Samples of about 5 to $10 \mathrm{mg}$ were run at a heating rate of $10^{\circ} \mathrm{C} / \mathrm{min}$ under a nitrogen atmosphere between 30 and $150^{\circ} \mathrm{C}$ to remove any previous therma history.

For Tg determinations, a heating rate of $20^{\circ} \mathrm{C} / \mathrm{min}$ was used, because the $\mathrm{Tg}$ is more pronounced at faster heating rates ( ASTM D 3418-03).

A dynamic mechanical analyzer (DMA-7e, Perkin Elmer) was used to confirm the Tg values of the composites.

The sample dimensions were $4 \times 2 \times 20 \mathrm{~mm}$. The samples were tested by bending at three points with a $15 \mathrm{~mm}$ support span. The test was dynamic with a temperature range of $30^{\circ} \mathrm{C}$ to $150^{\circ} \mathrm{C}$ at a heating rate of $5^{\circ} \mathrm{C} / \mathrm{min}$. A load frequency of 1 Hertz was used.

The thermal stability of pure PS (virgin and recycled) and silica-rPS composites was investigated by non-isothermal thermogravimetric analysis, using a TGA Q 50 TA Instruments.

Measurements were conducted at a heating rate of $10^{\circ} \mathrm{C} / \mathrm{min}$ in a nitrogen atmosphere and with a temperature range of $25^{\circ} \mathrm{C}$ to $600^{\circ} \mathrm{C}$. The average sample mass was about $4 \mathrm{mg}$.

The melt flow index (MFI) of virgin PS, rPS and silica-rPS composites was measured at $190^{\circ} \mathrm{C}$ under the applied load of $2.16 \mathrm{kgf}$ according to ASTM D 1238, using a MFI Dynisco LMI 4000.

Scanning electron microscopy (SEM) images of fracture surfaces were obtained using a JEOL microscope (Model jfm $6380 \mathrm{lv}$ ). The samples were gold-leaved to obtain the electronic images to examine the dispersion of silica in rPS composites.

The Izod impact test was performed at room temperature, according to the ASTM standard D 256-03 for ten pieces with notched test samples in a DYNISCO-API pendulum impact test machine.

A parametric analysis of variance (ANOVA) was performed on the data collected from the mechanical tests to distinguish statistical differences ( $p \leq$ 0.05 ) among the sample properties. All statistical analyses were performed using Statgraphics Plus software.

\section{RESULTS AND DISCUSSION}

Thermal behavior

The DSC results are summarized in terms of Tg in Table 1.

Table 1. Tg values of PS, rPS and nanosilica-PS composites obtained from DSC and DMA.

\begin{tabular}{|c|c|c|}
\hline Sample & $\operatorname{Tg}\left({ }^{\circ} \mathrm{C}\right)(\mathrm{DSC})$ & $\operatorname{Tg}\left({ }^{\circ} \mathrm{C}\right)(\mathrm{DMA}) \mathrm{E}^{\prime}$ \\
\hline PS & 92.7 & 88.2 \\
\hline rPS & 102.8 & 100.6 \\
\hline rPS 1\% & 102.4 & 99.4 \\
\hline rPS 3\% & 103.2 & 101.3 \\
\hline rPS 5 $\%$ & 104.5 & 102.0 \\
\hline
\end{tabular}
PS).

This table shows a higher Tg for $\mathrm{rPS}$ ( ca. $10^{\circ} \mathrm{C}$ above that of the virgin

The Tg of the rPS was not significantly affected by the silica nanoparticles.

As it is reported in the literature for PS and other virgin polymers, ${ }^{28,29,30} \mathrm{a}$ wide variety of polymer nanocomposites have shown interesting changes in the bulk glass transition behavior. Most researchers report an increase in the $\mathrm{Tg}$ as a function of filler content, however, decreases in the $\mathrm{Tg}$ have also been found. ${ }^{31,32}$ Table 1 shows that 1,3 and 5\% silica does not affect the Tg of rPS, which produces no change in the stiffness of the composites.

The higher Tg values of rPS and their derived nanosilica-rPS composites with respect to virgin PS were due to the additives used in the manufacture of EPS. These additives had some degree of physical adhesion with PS, which suggests that the chain mobility was restricted, which increased $\mathrm{Tg}$.
Figure 1 shows the storage modulus ( E' ) and tan $\delta$ of PS, rPS and rPS with $5 \%$ of nanosilica.

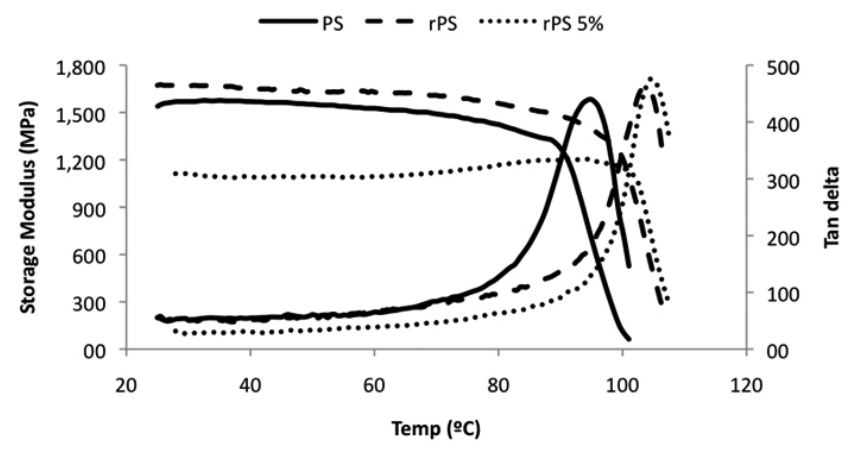

Figure 1. DMA curves of PS, rPS and rPS with 5\% nanosilica.

The storage modulus (E') is a measurement of stiffness and shows the temperature where a polymer changes from a glassy state to another viscoelastic.

The decline of the E' curve and the peak of $\tan \delta$ also showed a higher Tg for $\mathrm{rPS}$ and their composites. Other studies show similar results by adding 4,8 and $10 \%$ of nanosilica to virgin PS. ${ }^{3}$

The thermal decomposition profiles comparing the thermal stability of the virgin PS and rPS- composites as a function of nanosilica filler are shown in Figure 2.

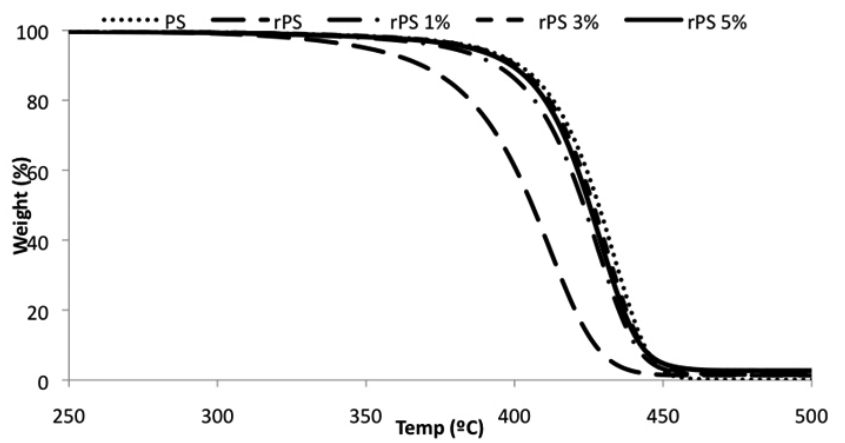

Figure 2. TGA curves of the PS, rPS and $\mathrm{rPS} / \mathrm{SiO}_{2}$ nanocomposites.

As shown in Figure 2, the decomposition of all polymers ocurred in one step.

rPS shows a lower thermal stability compared with virgin PS. rPS decomposition starts at $303^{\circ} \mathrm{C}$ with maximum weight loss rate (DTG) of $412^{\circ} \mathrm{C}$. The addition of 1,3 and $5 \%$ of nanosilica produce a rice of the decomposition temperature initiating thermal degradation at $320^{\circ} \mathrm{C}$, to levels similar to virgin PS $\left(324^{\circ} \mathrm{C}\right)$ with $\mathrm{DTG}$ of $428^{\circ} \mathrm{C}$, very similar to virgin PS $\left(430^{\circ} \mathrm{C}\right)$. The presence of nanosilica may have retarded or delayed the onset of the thermal degradation of the rPS.

This phenomenon has also been reported for virgin PS with other nanofiller. ${ }^{21}$

The polymer melt flow rate is a property that is associated with the rheological behavior of materials and it is used industrially for raw material quality control before processing. Recycled polymers generally have higher MFI values increased due to degradation of the molecular weights with increasing number of processing cycles. ${ }^{33}$

The melt flow behaviour of virgin PS, rPS and nanosilica- rPS composites was characterized by MFI measurements

Figure 3 shows the MFI values of the polymers. 


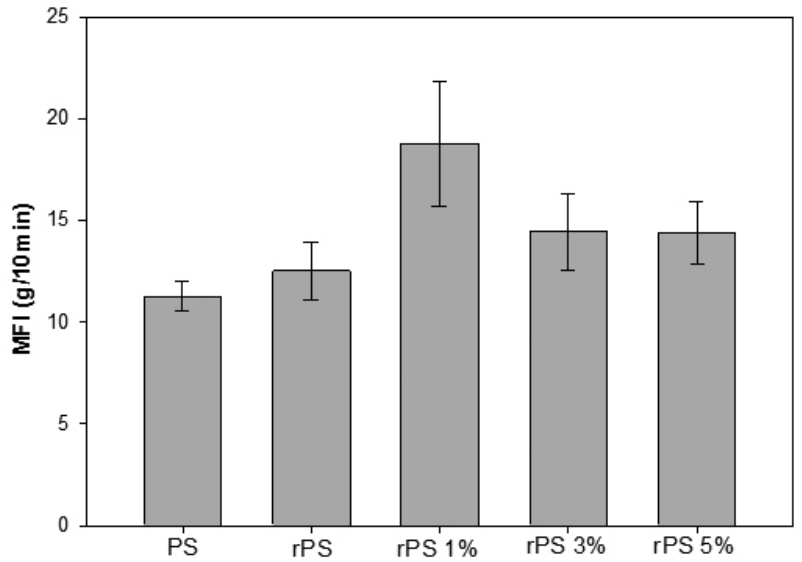

Figure 3. Effect of nanosilica content on the MFI of the nanocomposites

Figure 3 shows a slight increase in the MFI value of rPS (12.5 g/10min) regarding virgin PS (11.2 g / 10min), which is common in recycled polymers due to phenomena of molecular chain scission. By adding $1 \%$ of nanosilica at rPS produces the highest MFI $(18.7 \mathrm{~g} / 10 \mathrm{~min})$ due to increased degradation of the molecular weights of rPS with processing at $190^{\circ} \mathrm{C}$ in the mixer.

The addition of 3 and 5\% of nanosilica decreases MFI values to 14 $\mathrm{g} / 10 \mathrm{~min}$, because the higher content of nano-silica increases the viscosity of the polymer by acting as filler. A similar phenomenon by adding nanoclay to virgin PS has been reported ${ }^{17}$.

\section{Morphlogical analysis}

SEM micrographs of fractured surfaces of virgin PS, rPS and rPS containing $5 \%$ of nanosilica are shown in Figure 4.

The percentages of 1 and $3 \%$ of nanosilica were not clearly visible and therefore were not shown in the figure. It is noted that there is a higher level of lamination in the rPS (b) and the composite with nano-silica (c) compared with virgin PS (a).

It is observed in (c) small light-colored dots that represent the nanosilica particles distributed at random and without an uniform dispersion. An appropriate distribution and dispersion of nanoparticles is important because many of the properties of the mixture are determined by this interaction.

In the nanosilica- rPS micrograph is observed that the distribution of the particle size is fairly uniform, it fluctuates between 2-8 $\mu \mathrm{m}$. In general, as shown in Figure 4, there is no substantial change in morphology between virgin PS, rPS and rPS/nanosilica composites.

Table 2 shows the notched Izod impact strength of the pure PS (virgin and recycled) and nanosilica-rPS composites. As shown in Table 2, the impact strength values of the pure rPS and rPS reinforced with nanosilica composites increased significantly with the recycling process.

Table 2. Impact strength of the virgin PS, rPS and nanosilica-rPS composites.

\begin{tabular}{|c|c|}
\hline Sample & Impact strength $(\mathrm{J} / \mathrm{m})$ \\
\hline PS & 2.37 \\
\hline rPS & 2.97 \\
\hline rPS 1\% & 2.84 \\
\hline rPS 3\% & 2.92 \\
\hline rPS 5\% & 2.97 \\
\hline
\end{tabular}

The incorporation of additives into the pure rPS obtained from expanded packing increased the viscoelastic behavior of the material increasing its impact strength.

PS virgin is a polymer having a low degree of crystallinity. rPS and rPS / nanosilica composites have lower degrees of crystallinity due to the presence of additives and silica, which increases the amorphous portion. This increases the energy absorption capacity and viscoelasticity, which increases impact resistance.

The same phenomenon occurred when rPS was used to replace virgin PS in different compositions. The impact strength increased along with the weight percentage of rPS in the blends. ${ }^{4}$
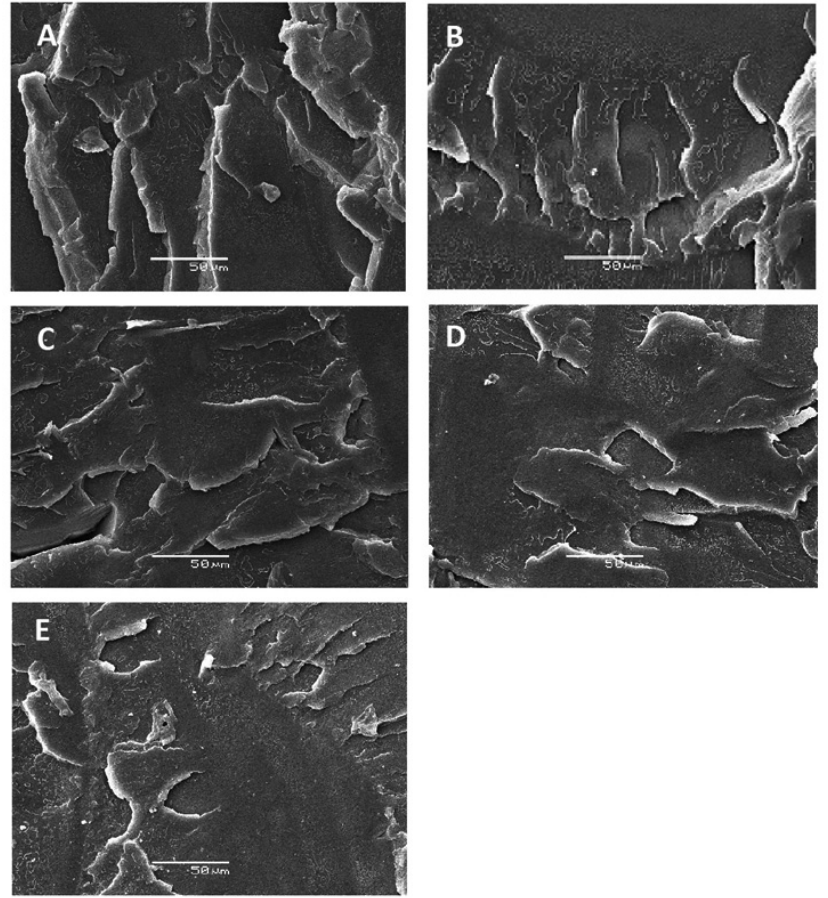

Figure 4. SEM microphotographs of PS (A), rPS (B), rPS with $1 \%$ nanosilica (C), rPS with 3\% nanosilica (D) and rPS with 5\% nanosilica (E).

\section{CONCLUSIONS}

The results of this study show that recycled polystyrene (rPS) from expanded polystyrene is a material with Tg, storage modulus (E') and impact strength of rPS higher than those virgin PS.

Incorporation of nano-silica in small percentages $(1,3$ and $5 \%)$ to $\mathrm{rPS}$ not have a significant influence on the $\mathrm{Tg}, \mathrm{E}$ ' and impact strength values, but increases the thermal stability of rPP to similar values to those of virgin PS .

The low influence of nano-silica in rPS may be associated with a poor dispersion of nanoparticles in the polymer matrix, as shown in SEM micrographs. This may occur because the mixing process in the polymer melt was insufficient.

On the other hand, the impact strength of the rPS and nanosilica-rPS composites were higher than virgin PS showing that it is feasible to obtain composite materials with good thermal and mechanical properties with recycled polystyrene in an attempt to reduce the disposal of postconsumer PS into the environment.

\section{ACKNOWLEDGEMENTS}

Financial support for this study was granted by the Research Center of Advanced Polymers ( Centro de Investigación de Polímeros Avanzados. CIPA) and the DIUBB 094906 project.

\section{REFERENCES}

1. R.M.N. De Assuncao, B. Royer, J.S. Oliveira, G.R. Filho, L.A. De Castro, J. Appl. Polym. Sci. 96,1534, (2005)

2. D. Maldas, B.V. Kokta, Polym Compos. 11, 77, ( 1990)

3. E. Kontou, G. Anthoulis, J. Appl. Polym. Sci. , 105, 1723, (2007)

4. G.J. Xu, J. Qiao, C. Kuswanti, K. Koelling, J.A. Stuart, B. Lilly, J. Appl. Polym. Sci. 84, 1, (2002)

5. A.L. Leite, J. Kloss, E.M. Trindade, R.V. Barbosa, A.R. Cestari, E. Fragoso, S.F. Zawadzky, J. Appl. Polym. Sci. 104, 2714, (2007).

6. Z. Horák, D. Hlavatá, I. Fortelny, F. Lednicky, Polym. Eng. Sci. 42, 2042, (2002)

7. H. Ismail, M. Nasir, Polym. Test. 2002, 21, 163 (2002)

8. M.E. Fowler, H. Keskkula, D.R. Paul, Polymer, 28, 1703 (1987)

9. T.Y. Guo, M.D. Song, G.J. Hao, B.H. Zang, Eur. Polym. 37, 241 (2001)

10. C.D. Park, N.H. Jo, M.S. Lee, Polymer, 37, 3055 (1996) 
11. C. da Silva, G.R.Filho, R.M.N. de Assuncao, M.Zeni, K.Mello, J. Appl. Polym. Sci. 104, 909 (2007)

12. J.Lisperguer, X. Bustos, Y. Saravia, J. Appl. Polym. Sci 119, 443 (2011)

13. M. Alexandre, P. Dubois, Mater. Sci. Eng. 28, 1 (2000)

14. J.Zhao, A. B. Morgan, J.D. Harris, Polymer, 46, 8641 (2005)

15. J. He, Y. Shen, J. Yang, D. G. Evans, X. Duan, Chem. Mater. 15, 3894 (2003)

16. J. He, Y. Shen, D. G. Evans, Microporous Mesoporous Mater. 109, 73 (2008)

17. U. Yilmazer, G. Ozden, Polym. Compos. 27, 249 (2006)

18. S. Djoumalinsky, P. Zipper, Macromol. Symp. 217, 391 (2004)

19. S. Siengchin, J. Karger-Kocsis, R. Thomann, J. Appl. Polym. Sci. 105, 2963 (2007)

20. Z.Wang, G.Li, H.Peng, Z.Zhang, X.Wang, J. Mater. Sci. 40, 6433 (2005)

21. C.C.Ma, Y.J.Chen, H.C.Kuan, J. Appl. Polym. Sci. 98, 2266 (2005)

22. F.L.Beyer, N.C.B.Tan, A.Dasgupta, M.E. Galvin, Chem. Mater. 14, 2983 (2002)
23. C. Dazhu, Y. Haiyang, H. Pingsheng, Z.Weian, Compos. Sci. Technol. 65, $1593(2005)$

24. T.E.Chang, A. Kisliuk, S.M. Rhodes, W.J.Brittain, A.P.Sokolov, Polymer , 47, 7740 (2006)

25. Z. Wang, M. Lu, H.L. Li, X.Y. Guo, Mater. Chem. Phys. 100, 77 (2006)

26. S.W. Lye, H. S. Aw, S.G.Lee, J. Appl. Polym. Sci. 86, 456 (2002)

27. X. Fu, M. Ding, C.Tang, B. Li, Z. Zhao, D-Q. Cheng,Q. Zhang Q.Fu, H.Long T.Tang, J. Appl. Polym. Sci. 109, 3725 (2008)

28. B.J. Ash, R.W.Siegel, L.S. Schadler, J.Polym.Sci. Part B: Polym. Phys. 42, 4371 (2004)

29. M. A. Perez, B.L.Rivas, S.M.Rodriguez, A. Maldonado, C.Venegas, J. Chil.Chem. Soc. 55, 440 (2010)

30. L.D. Pérez, J.F. López, V.H. Orozco, T. Kyu, B.L.López, J.Appl.Polym. Sci.111, 2229 (2009)

31. F. Orellana, J. Lisperguer, P. Pérez, J. Chil. Chem. Soc. 56, 668 (2011)

32. K. Sanjay, S. Mohanty, J.Appl. Polym. Sci. 112, 778 (2009)

33. M.H.Martins, M.A. De Paoli, Polym.Degrad. Stab. 78, 491 (2002) 